\title{
Threads, wefts and fabrics... visual constructions between photography and printmaking
}

Quote: TROCELLO, Micaela. Threads, wefts and fabrics... visual constructions between photography and printmaking. Porto Arte: Revista de Artes Visuais. Porto Alegre: PPGAV-UFRGS, v. 23, n. 38, p.91-96, jan.-jun. 2018. ISSN 0103-7269 | e-ISSN 2179-8001. DOI: http://dx.doi.org/10.22456/2179-8001.80779

Translated by Roberto Cataldo Costa

Abstract: This article presents a poetic production where printmaking and photography are deeply related. They are works with strong female presence, including Argentina's popular cultures and historical figures.

Keywords: Photography. printmaking. Female.

Within the universe of Visual Arts, I will try to address and point out a series of experiences typical of my personal creativeconstructive process, which were developed throughout my transit and successive appropriation.

This series of experiences is located between two traditionally definable disciplines - Printmaking and Photography - although we will see that, in many steps of the process, the definitions regarding corporeal or material results are characterized by lack of definition, better yet, by miscegenation.

Since my earliest works, printmaking and photography have been possibilities for expression, vehicles for thoughts and ideas at the visual level.

As if it were about weaving a blanket, printmaking and photography play the roles of weft and warp, as links of concepts and techniques, ideas and manufactures in the complex actions of making images. The blanket grew multiform. It had/has/have/will have its times as a more closed and rigid weft and others as an open and flexible one, allowing the conception of new stitches ${ }^{1}$ or construction strategies. At times, the blanket's permeable weft allowed me to nourish the fibers with new pigments; at other times, its character became impermeable as a poncho stitch².

I see the creative process as an inner pathway toward ourselves, toward that deep, profound genuineness interpreting originality not as something "novel" or "never seen", but

1. Translator's note: The Spanish WORD for stitch is punto, which is the same for point, or dot.

2. According to the Spanish dictionary of the Real Academia Española [accessed on June 2016]: Available at www.rae.es as something that leads us to our own individual origin, the beginning, birth, source, root and cause. ${ }^{3}$

Whatever we have to express is already with us, it is us, so the work of creativity is not about making the material emerge but rather unblocking the obstacles to its natural flow. ${ }^{4}$

In meanings woven from my condition as a biological woman and my identity within the female gender, from my minimal history, although immersed in a specific social, cultural and temporal context (both broad and limiting), and from my stance as a visual artist, I weave this original struggle that will certainly last my whole life.

The blanket metaphor allows me to introduce, in the whole processual construction, besides disciplinary or technical aspects, those that build the discourse - or discourse - of my images, that is to say, the concerns and interests that have been present along my pathway as a producer of images. I believe that virtually all my series or visual projects can be defined as socio-historical investigations referring to female gender problems in different cultural contexts.

From here, it is interesting to observe both considerations and references to artists and art critics made by Grabowski and Fick in their book El Grabado y la Impresión (2015), regarding, on the one hand, the necessary closing of (historical-traditional) hierarchical-Kantian gaps between "art" and "craft", and on the other, the emphasis and/or the value ascribed to specific procedures in our area, in direct connection with meaning-making. That means conceiving the work in all its stages of construction as an integral whole. A permanent dialogical relationship between idea, matter and technique. A constitution of the work/image as necessarily miscegenated as original (from origin).

Focusing on these procedural experiences, the un-drawing of the boundaries between photographic technique and printmaking technique(s) was an initial practice, both accessible and frequent, in the instances of knowledge and study of both disciplines as in the decision - or need? - to resort to them when exercising resolution and materialization of my works.

3. According to the Spanish dictionary of the Real Academia Española [accessed on June 2016]: Available at www.rae.es.

4. Nachmanovith, 2013, p.23-24. 
This very early miscegenation in my learning and artistic production experience is closely related to the relevance pointed out by Dominique Baqué in her book La Fotografía Plástica (2003):

It is not about the so-called "creative" photography or journalistic photography or applied photography; it is photography as it is used by artists; that which is not part of a supposedly pure and autonomous history of the medium but, on the contrary, that which cuts through the visual arts and takes part in the generalized hybridization of the practice, in the increasingly explicit disappearance of separations between distinct production fields.

Therefore, I also need to clarify and link - myself - in the current panorama of printmaking with the words of Maria del Mar Bernal Pérez (2016) in this regard:

Understanding today's graphic works involves an opening exercise and a process of adaptation to technical and iconographic change of the segments involved. Printmaking is now a territory in which the integration of all arts allows us to cross its borders with fluidity. ${ }^{5}$

I believe that both considerations are exemplified on a personal level by the fact that in the last year of my undergraduate studies in printmaking, a small experimental workshop of photographic technique and laboratory was offered, sharing the physical space with classes of, for instance, screen printing and rotogravure techniques such as etching. Together with photography, these methods were conceptually and procedurally linked, which allowed me to conceive my first photogravure works.

Chemical exploration and experimentation, but also, on a poetic/subjective level, a magical/playful approach to transforming matter. Thus, within the darkroom, the experience of witnessing the birth of the latent image formed in a photographic material as a result of exposure to light - invisible in its first condition and then turned visible by different development procedures - has become a daily ritual in the last 20 years of my work.

The act of developing as a polysemic ritual

In its latent version, image, subject to various liquids that are going to develop or revealo it, can emerge from the bottom of the tray, either on the white surface of the paper or in the greenish blue of photosensitive emulsions, until it becomes

5. Los nuevos territorios de la gráfica: imagen, proceso y distribución [accessed in June 2016]: Available at http://revistas.ucm.es/index.php/ARIS/article/view/47545. 6. Translator's note: The Spanish Word for developing a photographic film is revelar, or revealing. definitively visible. And here, I would like to pay attention to the Spanish word revelar (revealing), which in its first and second meanings implies to discover or manifest what is ignored or secret, to provide indications or certainty about something, and only in its last meaning refers to the action of rendering the image printed on the photographic plate or film visible. ${ }^{7}$

In the weaving-the-weft metaphor I incorporate each one of these meanings since they allow ascribing deep meanings to a chemical procedural action - a technical methodology. And, focusing on the discourses of my visual productions, the idea of revealing may be a recurring exercise or practice: providing clues or certainty about one's own family history, gender hierarchies, roles, in the series (under construction) The Cleavage is to Blame (La culpa fue del escote); providing clues about forgotten women in history, manifesting their ignored exploits, in the Warrior Loves (Amores Guerreros) project, 2014-18; discovering and expressing femininity in Gypsy culture, negatively ignored in contemporary social construction, a project carried out in 2010-11; rendering women visible and allowing them to express themselves in their secrets, yearnings and fantasies, in project Fictional Constructions, Daily Spaces (Construcciones Ficcionales, Espacios Cotidianos), 2009.

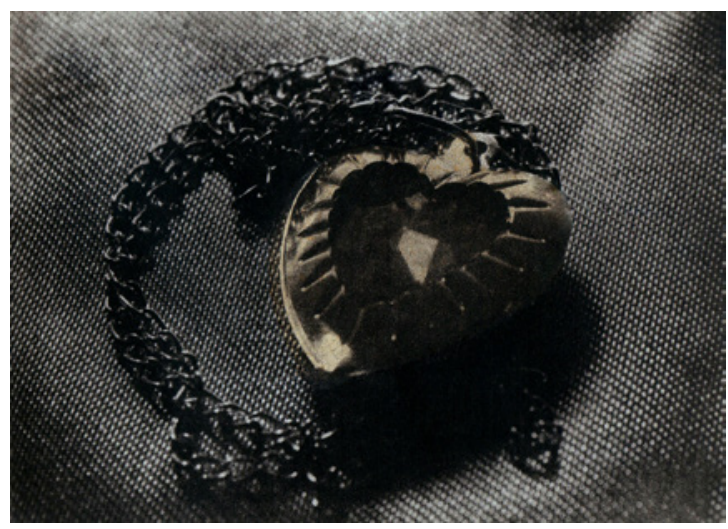

Figure 1. Micaela Trocello. No title. 2011. Photographed in polymer film on aluminum plate. Chine collé, $15 \mathrm{~cm}$ x $21 \mathrm{~cm}$. From the series Hate me for the Sake of Pity. Photo: Micaela Trocello

I am always accompanied by the same anxiety, intensity and surprise, although satisfaction is not always plain in the final result, but, as we know, it is a classic love burden typical of printmakers, and in this context, performing the ritual will

7. Diccionario de la lengua española de la Real Academia Española [accesed in June 201616]: Op. Cit. 
always be worth it, by "revealing" silver or iron salt papers, polymer film for the production of photogravures or offset plates for water-free photolithography matrices as in the Hate me for the Sake of Pity (Ódiame por Piedad) series (fig. 1).

To "develop" or "reveal" (myself), to discover (myself) and to manifest (myself) in my role as an artist implies both risk and daily work in the dynamic and open process of existence itself.

\section{THE POINT AS A SHARED VISUAL REALITY}

In the $15^{\text {th }}$ century, printmaking allowed us to reproduce and multiply the same image in the same way without the human hand having to copy it every time. In the 19th century, photography also allowed us to record a trace of the same reality without an intermediary hand. When the multiplicity of engraving is added to the objectivity of photography in photomechanical procedures, the two greatest visual inventions unite, with unforeseeable consequences. ${ }^{8}$

While Lemagny, among other issues, speaks of printmaking only as a method for reproducing images, he points to its origins as a "translator" of painting. He underscores the methodological or procedural strategies developed by printmakers throughout the history of the technique, trying to "interpret" these other images belonging to other languages in the best way possible.

Therefore, I would like to point out certain ideas of this author that are relevant to support my experiences regarding the subject in question and mention that his assertions about both disciplines are sometimes biased. I emphasize the relevance he ascribes to the graphic code, the invention of a system of conventional representation that is "very effective for our imagination's eye", already matching printmaking and photography. Apart from the fact that his interest is in photomechanical prints as reproductions, that is, copies of a photographic original, thus denying all artistic-expressive autonomy to printmaking in general and photomechanical techniques in particular, he circumscribes both disciplines under "the same visual reality" - a reality consisting of little points, silver grains or ink stains, but little dots still, which are identical when looked at. We can now add pixels as well.

It is perhaps here where I can comfortably locate myself in the making of my images, in the shaping of my visual productions: the point as a constituent element of visual language beyond discussions posed by the author about proximities and distances between the image as original and the image as a reproduction.

8. Lemagny, 2008, p.113
Perhaps it was this familiarity, this system of shared visual code that allowed me to move and transit not simultaneously but wholly between photography and (photomechanical) engraving: the intimate dialogue that happens in the conception and materialization of the images, obturating, revealing/ developing, intervening and transferring.

Weaving the blanket with photographic wefts and warps, digital or manual intervention of that/those takes and/or copies (whether analog or digital) and the making of the matrix - or matrices - by photomechanical procedures often allow me to arrive at the origin of a genuine and irremediably mestizo print. However, beyond these interesting procedural strategies and several instances charged with meanings, I would not want to reduce this familiarity between techniques, which ultimately happens from a purely formal perspective. The fluid passages of one image in the change of supports necessary for its definitive materialization "do not break the intimate fiber" since, as Lemagny points out, "they preserve the same visual continuity", and this fact allows me first to select and then to emphasize the very materials that constitute the work - for instance, cotton paper and graphic ink before photographic paper and digital printing. Here the intrinsic poetics of the very materials and the visual code shared by photomechanical - printmaking - and photography techniques collaborate in the poetics of my images, but I will try to move forward by pointing out other spaces of encounter.

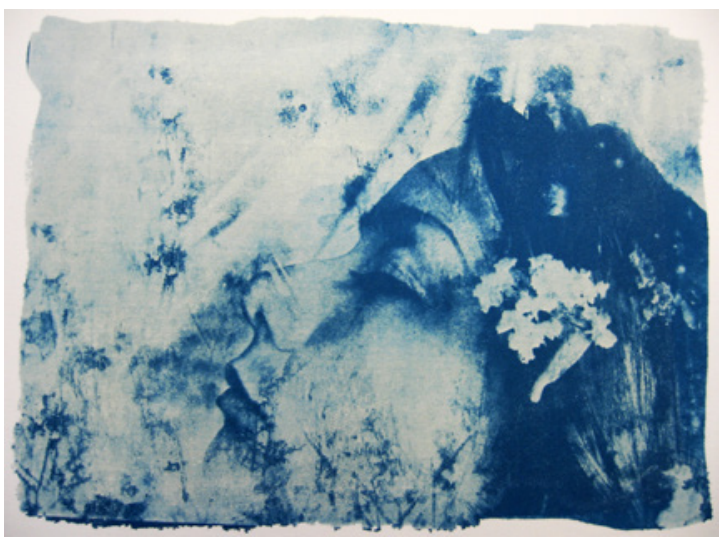

Figure 2. Micaela Trocello. The kiss that was not... 2009. Cyanotype on cotton paper. From the series Fictional Constructions, Daily Spaces. Photo: Micaela Trocello

We could speak of a concatenation of transfers in the sense of the changes in support to which I generally submit my images, moving from one surface - including the digital 
support - to another until they reach their concretion and final materialization. And in this interplay of passages, the possibility of incorporating new resources into the visual poetics of printmaking and photography, as in The kiss that was not ${ }^{9}$ (El beso que no fue) (fig. 2).

\section{THE MATRIX AS A MEETING POINT, AS A SHARED SPACE}

Therefore, there is no solution: the history of photography is the chronicle of a process of transubstantiation; it is the story of how the document becomes art. ${ }^{10}$

This section should start by mentioning the references to artist Dennis Oppenheim's work Reading position for $2^{\text {nd }}$ Degree Burn (1970) - which consisted of partially covering his bare torso exposed to the sun with an open book.

While Baque (2003, p.16) underscores that performance as an eminently photographic act, since the artist uses his own skin as if it were photographic film; Bernal Pérez (2013, p.227) emphasizes the idea of book-matrix that acted on a torso turned into a solar plate. In a double possibility, the body is a printing support and photosensitive material prone to being a support for recording, for a mark.

These references to the same work allow us to visualize the wide mestizo spectrum between printmaking and photography and the possibility of approaching the concept of matrix as shared specificity in such horizon of diversities. Crossings, encounters and openings about which there are of course several decades of conformation and discussion.

Sharing Grabowski and Fick's (2015, p.8) definition of "generative matrix" we understand that it is always a medium for transporting information as an image that is ultimately printed on another surface. And it serves both the possibilities offered by traditional practices (by drawing, printmaking or cutting a metal plate, for instance) and contemporary or experimental ones (elements found or re-signified).

In this context, the authors add: "A print can function as a photograph because of its ability to refer to the printed object. Like a photographic souvenir, the print made from a surface is a physical proof of the existence of that surface" (idem). We

9. Cyanotype on cotton paper, created from a first photographic analogue take, then going through digitization and intervention in the file by using dot filters, to later configure the negative in filmstrip that will result in the final image.

10. Fontcuberta, 2010, p.186. might even say that every matrix, in its different printed forms, leaves a trace of its existence. The cases of "proof of status"11 would be good examples, each of the prints being a direct and unique mark of that state of the matrix, at that time, in direct similarity with the photograph as a document. The testimonial specificity of prints is linked to what Barthes (2008, p.121) calls "the very essence of photography": the noema "that has been". The double "joint position of reality and past" is manifested, to a greater or lesser extent, also in prints resulting from any physical matrix. Let us consider the various materials used to date as constituent elements of the matrices and the successive wear of those materials from multiple printings. The transformations caused by water, the weight of pressure, the mechanical cleaning of inks among others are variables that will affect the distinct surfaces and will be often evidenced in the prints, acting as documents of themselves in the succession of a process of creation and construction.

\section{In The Lucid Camera, Barthes explains:}

I call "photographic referent" not the optionally real thing to which an image or a sign refers but the necessarily real thing which has been placed before the lens, without which there would be no photograph.

I propose to ask if the matrices made with the distinct techniques that the area of printmaking offered and offers according to their procedural treatment, their material or physical composition, to a lesser or greater degree, can act as a "photographic referent of themselves".

Linking to the above, I refer to the words of Martine Joly (2009, p.75): "The referent adheres, the photograph is a mark, and consequently, although 'similar' and fabricated, it is specific because it is an index in the Peircean sense of the term."

Referring to the complex analyses of Barthes and Dubois, Joly continues:

The consequences of such specificity are considerable. It links photography with the tradition of sacred images, with that of

11. Proof of status: During the process of intervention in the matrix, the graphic artist examines the development of his work and its effect on paper in successive stages. This verification is done by printing the matrix as it is found (...) Insofar as the results vary considerably from one proof of status to another, as a consequence of adding or subtracting elements, each of them will be unique, because, even if the artist tried - which would be meaningless - it would be impossible to return with absolute accuracy to previous statuses. Their uniqueness and rarity have made these proofs highly sought after by collectors and printmaking galleries. Whoever is fortunate enough to gather all the proofs of status will be able to know the creative stages of a print step by step (Blas, 1996). 
truth-images, with magic, with hallucinatory madness, with death. It feeds the confusion between real visible - reality and truth.

Therefore, I would like to bring up my Offer (Ofrenda) series - a tribute to Carme Puch de Güemes, where I evoke a historical event through bodily reconstruction or "incarnation" in which the widow of General Güemes, upon learning of the death of her husband, decides to cut her hair (fig. 3).

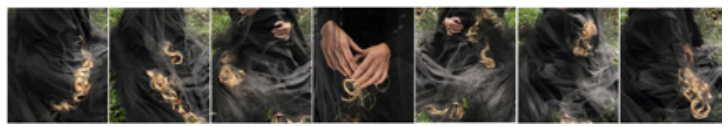

Figure 3. Micaela Trocello. No title. 2014. Direct take digital color photography. Seven-piece polyptych, $45 \mathrm{~cm} \times 55 \mathrm{~cm}$ each. From the Offer (Ofrenda) series. Photo: Micaela Trocello

Likewise, it is precisely this character of index reserved with so much zeal for photography throughout its existence (in the social construction of the medium, by both producers and consumers) which I find possible to reserve for printmaking: a shared specificity, being a sign by physical connection. Such physical connection is given precisely by the matrix. The luminous mark of the referent, printed on the silver film and even electronically on a digital file and the mark made by any (mechanical, chemical) procedure on a surface such as metal or wood. This procedural-conceptual weft is evident in the Female (Hembra) series, where, after taking the direct photographs in 35mm black-and-white film, I intervene on each negative, cutting, scratching, scraping with various elements as if they were iron or aluminum plates (fig. 4).

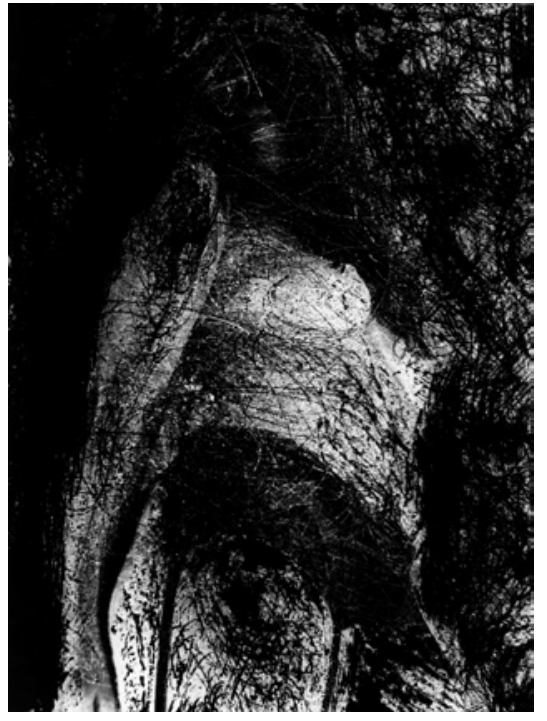

Figure 4. Micaela Trocello. Untitled. 2004. Single manual copy on Ilford photographic paper. $30 \mathrm{~cm}$ x $40 \mathrm{~cm}$. From the series Females (Hembras). Photo: Micaela Trocello
Continuing with the concept of matrix, Joan Costa, in La Fotografía. Entre sumisión y subversión, places it as one of the six specific features that will define the very nature of photography as such: "Since Fox Talbot, the photographic image is indirect, unlike the manual image that is always direct and immediate. Between reality and the photographic image there is an intermediate, mediating counter-image, which is the negative" (Costa, 1991, p.47).

As we can see, there is no space here, no fissure where printmaking can enter at least as a co-heir (traditionally and historically) of this specific feature. While Costa points out that the photographic negative "has given the medium the quality of a multiplier matrix of the same image and introducing innumerable variants in it - the idea of 'infinite image' (Idem, p.51) - for a few visual artists, this quality extends to the infinite possibilities offered by the increasingly expanded universe of contemporary graphic work".

Among old and new practices and technologies, among re-significations of the printmaker's and the photographer's crafts, among the persistent and fluctuating questions in my role as an artist, I continue weaving this struggle, this original blanket, wefts, meanings, the female gender ... art and life.

\section{REFERENCES}

BAQUE, D. La fotografía plástica. Barcelona: Gustavo Gili, 2003. BARTHES, R. La cámara lúcida. Buenos Aires: Paidós, 2008.

BERNAL, M. M. tecnicasdegrabado.es [Difusión virtual de la gráfica impresa]. Tenerife: La Laguna, 2013. Available at http://tecnicasdegrabado.es/etiqueta/ tecnicasdegrabado-es-difusion-virtual-de-la-grafica-impresa BERNAL PÉREZ, M. M. Los nuevos territorios de la gráfica: imagen, proceso y distribución. Arte, Individuo y Sociedad. Madrid, Vol. 28, n. 1, p. 71-90. 2016. [Accessed in June 2016]: Available at http://revistas.ucm.es/index.php/ARIS/ article/view/47545

BLAS, J. (Ed.). Diccionario del dibujo y de la estampa... "Diccionario del Arte Gráfico". Madrid: Real Academia de Bellas Artes de San Fernando, 1996.

CORCUERA, R. Herencia textil andina. Buenos Aires: Fundación Ceppa, 2010.

COSTA, J. La fotografía. Entre sumisión y subversión. México

D.F.: Trillas: SIGMA, 1991.

DICCIONARIO de la lengua española, de la Real Academia 
Española [Accessed in June 2016]: Available at www.rae.es FONTCUBERTA, J. La cámara de Pandora. La fotografía después de la fotografía. Barcelona: Gustavo Gili, 2010.

GRABOWSKI, B. y FICK, B. El Grabado y la Impresión.

Barcelona: Blume.

JOLY, M. La imagen fija. 2009. Buenos Aires: La Marca, 2015.

LEMAGNY, J.C. La sombra y el tiempo. La fotografía como arte.

"Grabado y fotografía. O la piel de las cosas". Buenos Aires:

La Marca, 2008.

Micaela Trocello: was born in Córdoba, Argentina 1978. Graduated in Engraving at the National University Córdoba. Diploma in Investigation and Conservation of Documental Photography, Faculty of Philosophy, UBA. (2018 - 2011) She studies photogravure in polymer film with Graciela Buratti. Artist in Resident FUNDACIÓN ACE (2016 y 2012) Buenos Aires. AWARDS, MENTIONS Y SELECTIONS: (2017) Honorable Mention 1st International Identity Diversity Call. Autonomous University of Entre Ríos. Argentina. (2017) El Pliego/ University of Vigo, Spain. (2016) Korean Contemporary Printmakers Association. Korea, 16th INTERNATIONAL BIENNIAL OF SMALL GRAPHICS ÓSTROW WIELKOPOLSKI 2016. Poland. GUANLAN 2013, Biennial International, Mission Hills, China. XVII FESTIVAL DE LA LUZ 2012. Bs.As. (2010 y 2012) Finalist II y III Prize ATLANTE, Spain. PREMIO FUNDACIÓN WILLIAMS 2012. (2009) Acquisition Award SALVADOR CAPUTTO,LXXXVI SALÓN DE MAYO, Argentina.

(*)This text was sent in August 2017. 